\title{
How Multiple Sclerosis Symptoms Vary by Age, Sex, and Race/Ethnicity
}

Ilya Kister, MD, Tamar Bacon, BA, and Gary R. Cutter, PhD

Correspondence

Dr. Kister

Neurology: Clinical Practice August 2021 vol. 11 no. 4 335-341 doi:10.1212/CPJ.0000000000001105

ilya.kister@nyulangone.org

\section{Abstract}

\section{Objective}

Little is known about how symptom severity in the various neurologic domains commonly affected by multiple sclerosis (MS) varies by age, sex, and race/ethnicity.

\section{Methods}

This was a retrospective study of patients with MS attending 2 tertiary centers in the New York City metropolitan area, who selfidentified as White, African American (AA), or Hispanic American (HA). Disability was rated with Patient-Determined Disability Steps (PDDS) and symptom severity, with SymptoMScreen (SyMS), a validated battery for assessing symptoms in 12 domains. Analyses comparing race, sex, and age groups were performed using analysis of variance models and Tukey honestly significant difference tests to control the overall type I error. A multivariable model was constructed to predict good self-rated health (SRH) that included demographic variables, PDDS, and SyMS domain scores.

\section{Results}

The sample consisted of 2,622 patients with MS (age 46.4 years; $73.6 \%$ female; $66.4 \%$ White, $21.7 \%$ AA, and $11.9 \%$ HA). Men had higher adjusted PDDS than women $(p=0.012)$, but similar total SyMS scores. Women reported higher fatigue and anxiety scores, whereas men had higher walking and dexterity scores. AAs and HAs had higher symptom domain scores than Whites in each of the 12 domains and worse SRH. In a multivariable logistic model, only pain, walking, depression, fatigue, and global disability (PDDS), but not sex or race/ethnicity, predicted good SRH.

\section{Conclusions}

AA and HA race/ethnicity was associated with higher overall disability, higher symptom severity in each of the 12 domains commonly affected by MS, and worse SRH relative to Whites. However, only symptom severity and disability, and not demographic variables, predicted good SRH.

Much has been written about symptoms of multiple sclerosis $(\mathrm{MS})^{1,2}$ but relatively little about how symptoms of MS vary by age, sex, and race/ethnicity. We have previously assessed symptom severity as a function of disease duration in MS. ${ }^{3}$ In this study, we compare MS symptom severity across the age spectrum in men and women of the 3 race/ethnic groups most represented in our

NYU Multiple Sclerosis Comprehensive Care Center (IK, TB), NYU Langone Medical Center, NY; and Department of Biostatistics (GRC), UAB School of Public Health, Birmingham, AL. Funding information and disclosures are provided th the end of the article. Full disclosure form information provided by the authors is available with the full text of this article at Neurology.org/cp.

The Article Processing Charge was funded by Biogen.

This is an open access article distributed under the terms of the Creative Commons Attribution-NonCommercial-NoDerivatives License 4.0 (CC BY-NC-ND), which permits downloading and sharing the work provided it is properly cited. The work cannot be changed in any way or used commercially without permission from the journal. 
practice-Whites, African Americans (AAs), and Hispanic Americans (HAs). Minority populations are increasingly affected by MS, ${ }^{4,5}$ but less than $1 \%$ of all MS studies have been devoted to them. ${ }^{6}$ A better understanding of similarities and differences in symptomatology of the different race/ethnicity groups is necessary to fully address the disparities that may exist in the care of non-White patients with MS. ${ }^{7-9}$

\section{Methods}

Consecutive patients from the New York University (NYU) MS Care Center (New York City, NY) and Barnabas MS Care Center (Livingston, NJ) self-identified their sex (but not gender) and race/ethnicity (White, AA, HA, and other) and rated their disability, symptom severity, and quality of health at the time of their scheduled doctor visit. Disability was rated with Patient-Determined Disability Steps (PDDS), an 8-point scale that measures global neurologic impairment in $\mathrm{MS}^{10}$ (available at 9369df97-4fc0-4f79-b0e9-183aa5f01c36.filesusr.com/ugd/ 826c66_b39d4958805541efbdf3dd2b81ec80d5.pdf). PDDS strongly correlates with the Expanded Disability Status Scale. ${ }^{11}$ Symptom severity was assessed with SymptoMScreen (SyMS, available at symptomscreen.org), a validated battery of 7-point Likert scales for 12 domains commonly affected by MS: mobility, dexterity, vision, fatigue, cognition, bladder function, sensory function, spasticity, pain, dizziness, depression, and anxiety, ${ }^{12}$ with higher scores indicating more impact of that domain on patients' functioning. Self-rated health $(\mathrm{SRH})$ was assessed with a single-response question used by the World Health Organization for the study of aging and global health: "In general, how would you rate your health today? Very good, Good, Moderate, Bad, or Very bad" (available at who.int/ healthinfo/systems/WHO-INDEPTH SAGE A.pdf?ua=1).

Inclusion criteria were age 18 years or older and a diagnosis of MS, which was confirmed by the treating clinician at the time of visit. We restricted analyses to the 3 main racial/ethnic groups in our sample, Whites, AAs, and HAs. Visits took place between June 2010 and December 2018. When there was more than 1 record for the patient, we used only the last available record for the analyses.

Analyses included descriptive statistics (means, median, and SD) and plots of mean scores by age group, sex, and race and means adjusted for the other variables. Analyses comparing race, sex, and age groups were calculated using analysis of variance models and Tukey honestly significant tests to control the overall type I error. A multivariable logistic model to predict good SRH (defined as response of "very good" $[=1]$ or "good" $[=2]$ on SRH) included demographic variables (age, sex, and race/ethnicity), disability (PDDS), and individual SyMS domain scores. All analyses were performed using JMP 14.2.0 and SAS 9.4 software; $p<0.05$ was considered statistically significant.

\section{Standard Protocol Approvals, Registrations, and Patient Consents}

The retrospective study used deidentified data and received an exemption determination from the institutional review boards of
NYU Langone Medical Center (New York) and Barnabas Medical Center (Livingston, NJ). Patient consent was not required.

\section{Data Availability}

Anonymized data not published within this article will be made available by request from any qualified investigator.

\section{Results}

\section{Demographic and Disease-Related Characteristics}

Of the 2,851 consecutive patients who met the initial inclusion criteria, 229 patients ( $8 \%$ of the sample) were excluded because they either declined to provide race/ethnicity or reported other race. Thus, the final sample consisted of 2,622 patients with MS from NYU $(\mathrm{n}=1,556)$ and Barnabas $(\mathrm{n}=1,066)$ MS Care Centers. Of 2,622 patient records, 1 domain was missing in 505 patients (19\%) and 2 domains were missing in 50 patients (1.9\%). The most common reason for missing domain was dizziness $(n=259)$, which was added later to the instrument than all the other domains. For individuals with the missing scores, we used imputation by calculating the average score for the items present and scaling these values to a 12-domain score. Demographics and disease-related characteristics of the sample are summarized in the table.

\section{Differences in Disability and Symptom Severity Between Men and Women}

Men had higher disability (PDDS) than women ( $p=0.012$, adjusted for race and age), but the total SyMS scores were similar for the 2 sexes $(p=0.39$, adjusted for race and age). SyMS scores in men and women stratified by age are shown in

Table Demographic and Disease-Related Characteristics

\begin{tabular}{ll}
\hline No. of patients & 2,621 \\
\hline NYU MS Center & 1,556 \\
\hline Barnabas MS Center & 1,065 \\
\hline Age, mean \pm SD & $46.4 \pm 13.0$ \\
\hline Sex, \% female & 73.6 \\
\hline Race, \% & 66.4 \\
\hline White & 21.7 \\
\hline African American & 11.9 \\
\hline Hispanic American & 81 \\
\hline MS subtype; \% relapsing & $2.19 \pm 2.22[1]$ \\
\hline PDDS, mean \pm SD [median] & $19.0 \pm 14.6[16]$ \\
\hline $\begin{array}{l}\text { Total SymptoMScreen, mean } \pm \text { SD } \\
\text { [median] }\end{array}$ & $1.3 \pm 0.9$ \\
\hline Self-rated health score, mean \pm SD & \\
\hline
\end{tabular}

Abbreviations: NYU = New York University; PDDS = Patient-Determined Disability Steps. 
Figure 1 Total SymptoMScreen Score in Women (Blue) and Men (Red) Stratified by Age

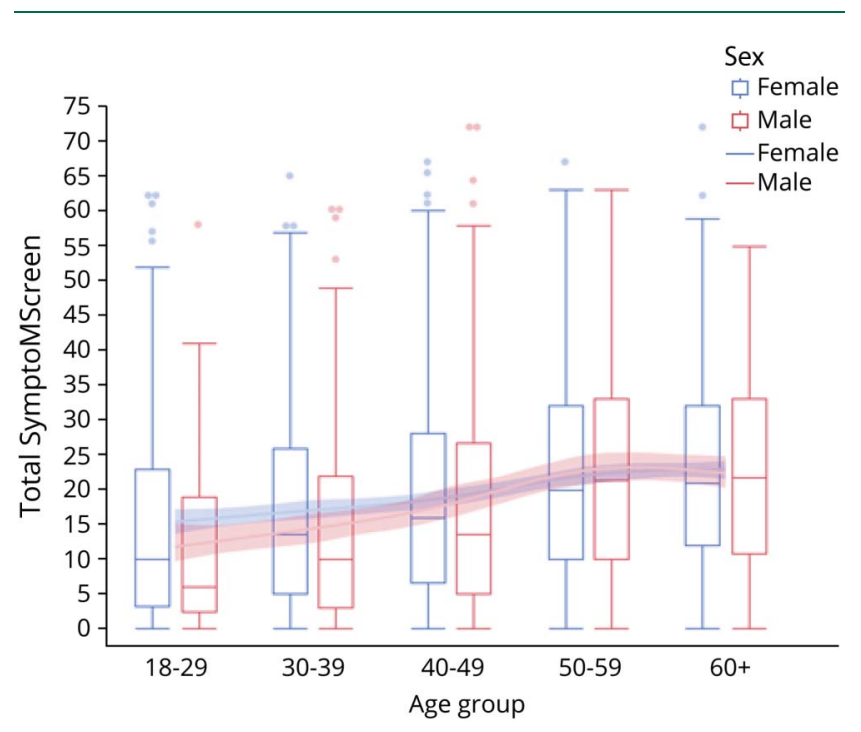

figure 1; there was a tendency toward higher scores in women in the 18-29 group $(p=0.09)$, and there were significantly higher scores in women in the 30-39 group $(p=0.047)$. In contrast, scores in the 3 older age brackets were similar; the interaction test was not significant $(p=0.15)$.

Men and women showed an increase in PDDS and total SyMS scores with age ( $p<0.0001$ for both, adjusted for race and sex), with the highest change between ages 40 and 59 years in both sexes (figure 1). Age group, race, and sex were all significant effects in the models, and no 2-way interactions were significant. With respect to individual domain scores, men had worse scores in the domains of walking (mean difference of $0.19, p<$ 0.013 , adjusted for age and race) and dexterity (mean difference of $0.15, p<0.028$ ) but better (lower) scores on the domains of fatigue (mean difference of $0.17, p=0.020$ ) and anxiety (mean difference $0.19, p=0.0071$ ). There were no significant differences between sexes in the other 8 domains. SRH was similar among men and women $(p=0.84)$.

\section{Differences in Disability and Symptom Severity Among Whites, AAs, and HAs}

The age-adjusted mean PDDS for AA and HA men and women were higher than for their White counterparts of the respective sex $(p<0.0001)$. Figure 2 (top panel) shows the unadjusted mean PDDS scores for each sex/race/age subgroup and the numbers of patients in each sex/race/age subgroup. The mean total SyMS scores among the 3 race/ ethnic group were also significantly higher in AAs and HAs than Whites after adjusting for age and sex ( $p$ values $<0.05$ via post hoc $t$ tests on the least squares adjusted means) (figure 2 , bottom panel). With respect to individual domains, AAs had significantly worse scores than Whites on all domains: walking (mean difference of $0.67, p<0.001)$, dexterity $(0.40$, $p<0.0001)$, spasticity $(0.50, p<0.0001)$, pain $(0.57, p<$ $0.0001)$, sensory $(0.43, p<0.0001)$, bladder function $(0.53$, $p<0.0001)$, fatigue $(0.44, p<0.0001)$, vision $(0.39, p<$ $0.0001)$, dizziness $(0.39, p<0.0001)$, cognition $(0.39, p<$ $0.0001)$, depression $(0.35, p<0.0001)$, and anxiety $(0.21, p=$ $0.0054)$. HAs also had worse scores than Whites in all domains: walking $(0.49, p<0.0001)$, dexterity $(0.43, p<$ $0.0001)$, spasticity $(0.60, p<0.001)$, pain $(0.81, p<0.0001)$, sensory (0.51, $p<0.0001)$, bladder function $(0.55, p<$ $0.0001)$, fatigue $(0.58, p<0.0001)$, vision $(0.58, p<0.0001)$, dizziness $(0.58, p<0.0001)$, cognition $(0.79, p<0.0001)$, depression $(0.60, p<0.0001)$, and anxiety $(0.56, p<0.0001)$. HAs had higher scores than AAs on domains of pain (0.24, $p<0.0001)$, cognition $(0.40, p<0.0001)$, depression $(0.25$, $p<0.023$ ), and anxiety $(0.25, p<0.026)$. Figure e- 1 (links. lww.com/CPJ/A299) shows unadjusted domain scores stratified by age and sex for each of the 3 race/ethnic groups. SRH was worse in AAs (mean = 1.43) compared with Whites $(1.15, p<0.0001)$ and was similar in AAs and HAs (mean = $1.48, p=0.43)$.

\section{Age-Related Trends of Domain Scores}

Age-related domain trends showed significant increases in men and women of each race/ethnic group (with the exception for anxiety, for which a decrease with age was observed). We therefore compared the age-related trends for the 12 domains with each other irrespective of sex and race/ ethnicity. Fatigue scores were markedly higher than scores in any other domain throughout the age spectrum, and especially in the younger patients, and were overtaken only by walking scores in the oldest age group (figure 3). A continuous increase in symptom scores throughout the age spectrum in the mostly spinal domains of walking, bladder, and, to a lesser degree, dexterity stood in contrast to the relative flattening with age in the cerebral domains of depression and cognition, which increased only before age 40 years, but not thereafter.

\section{Predictors of Good SRH}

We started with a logistic model to predict good SRH ("Very good" or "Good" responses) based only on age, race, and sex and overall disability (PDDS). This model was able to achieve an area under the receiver operating characteristic (ROC) curve of 0.78 , with race $(p<0.0005)$ and PDDS ( $p<$ 0.0001 ) being the 2 statistically significant predictors in the multivariable model. This model achieved $69 \%$ sensitivity and $77 \%$ specificity. When the individual domain predictors were added to the model, the area under the ROC curve was improved to 0.88 . In the expanded model, only 4 diseaserelated factors-body pain, depression, fatigue, and PDDS (in the order of decreasing contribution) - were significant predictors of good SRH, whereas age, sex, and race/ethnicity were not. The model had a sensitivity of $81.9 \%$ (95\% confidence interval [CI] 76.8\%-87.2\%), a specificity of $76.0 \%$ (95\% CI $69.6 \%-82.9 \%$ ), a positive likelihood ratio of 3.4 (95\% CI 3.0-3.9), a negative likelihood ratio of 0.2 (95\% CI $0.2-0.3$ ), a positive predictive value of $85.4 \%$ (95\% CI 
Figure 2 Patient-Determined Disability Steps (PDDS) Score in Women (Left) and Men (Right) Stratified by Age and Race/ Ethnicity (Top Panel) and Total SymptoMScreen Score in Women (Left) and Men (Right) Stratified by Age and Race/Ethnicity (Bottom Panel)

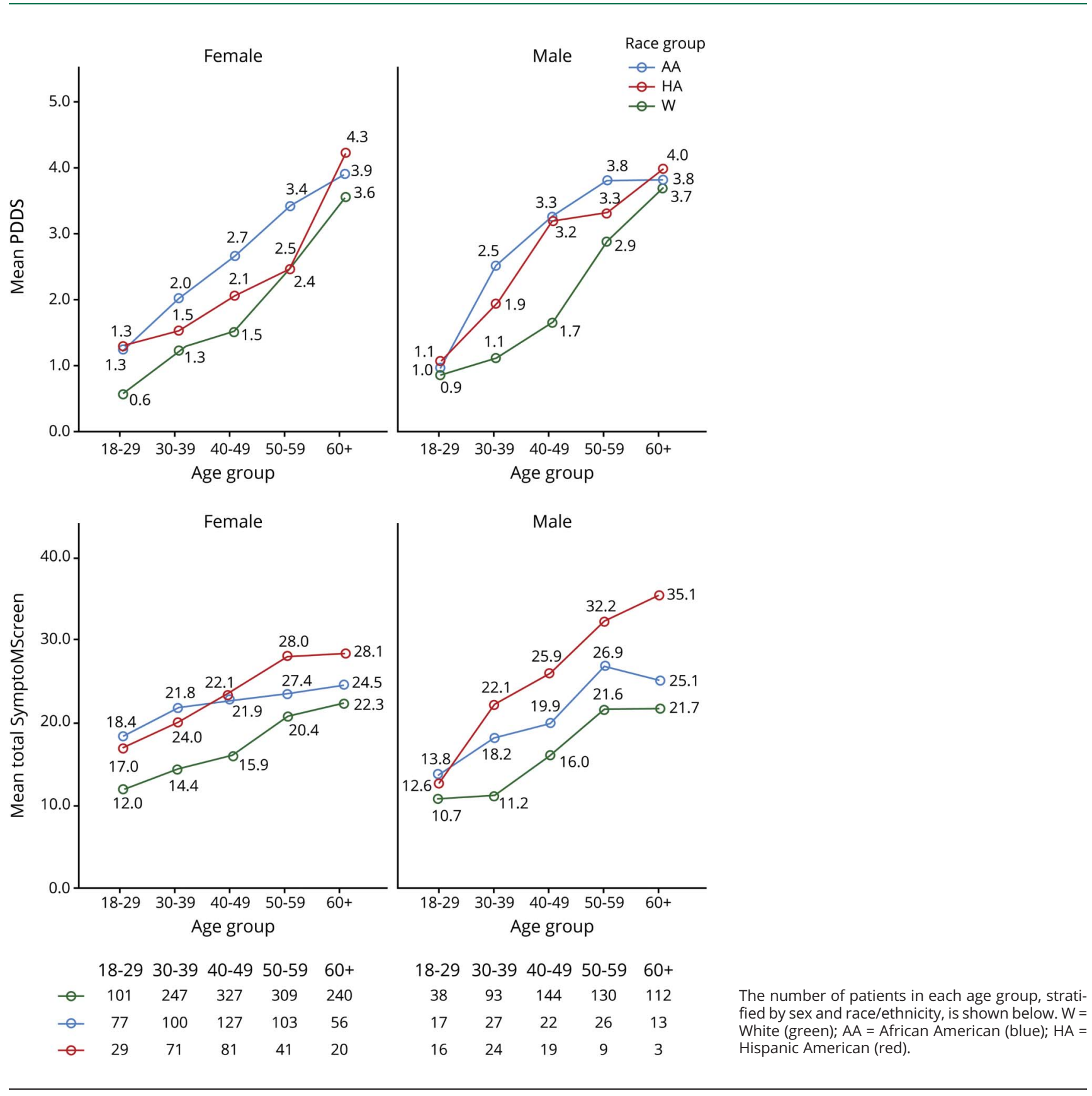

$83.6 \%-87.0 \%)$, and a negative predictive value of $71.0 \%$ (95\% CI 68.3\%-73.6\%).

\section{Discussion}

Disability and symptom burden increased with age in men and women of every race/ethnicity groups, as would be expected in a progressive neurologic disorder. The largest increase occurred between ages 40 and 60 years, perhaps a reflection of the transition from the relapsing phase to the progressive phase during this period in most patients. The change in symptom burden score between 50-60 and 60+ years' age groups was less pronounced, possibly because of the relatively slower progression in the older patients or because of psychologic accommodation to physical limitations (as reflected in lower anxiety and depression scores in patients aged 60+ years compared with the 50-60 age group). Immortal time bias, whereby older and severely disabled patients would be more likely to have died or be too impaired to follow up in the clinic, may also have contributed to the apparent flattening in total SyMS scores in the older groups. With the exception of anxiety, individual domain scores all showed an increase with age, but 


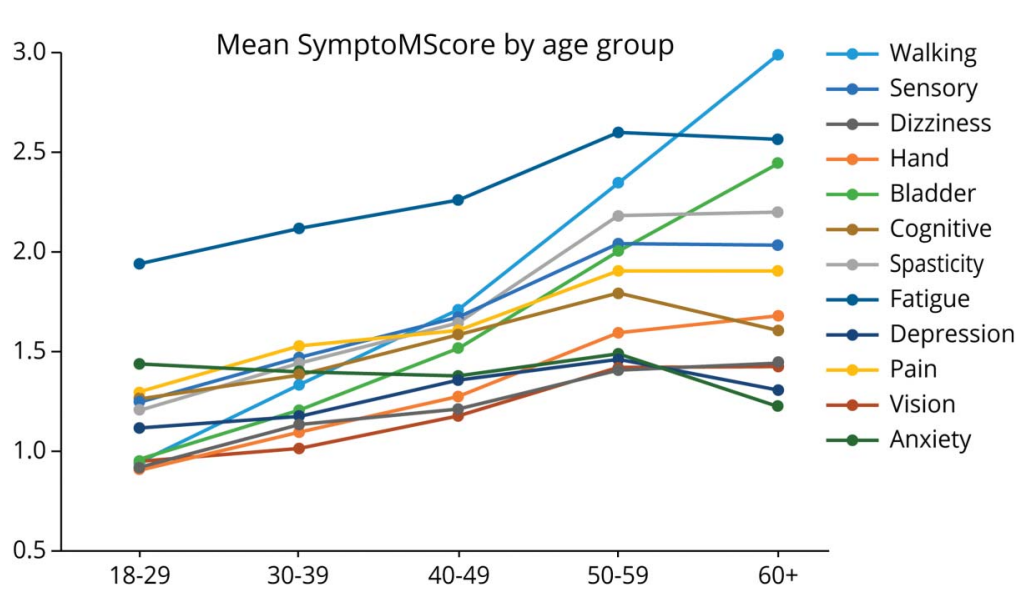

the pattern of increase differed between spinal domains, such as walking and bladder function, which steadily increased, and cognitive and affective domains, which tended to increase before age 40 years, but not thereafter. Worsening of physical disability with age and stabilization of mental health scores has been observed by others as well. $3,13,14$

Men and women had similar total symptom scores and similar SRH. Younger women (aged $<40$ years) tended to have higher total symptom scores than men of the same age, perhaps a reflection of a higher rate of relapse and enhancing lesion formation in women compared with men. ${ }^{15-17}$ Higher anxiety scores among women with MS may reflect a well-known predisposition of women to anxiety disorders. ${ }^{18}$ Women also had higher fatigue scores compared with men; similar findings of higher fatigue in women were reported in a recent multicenter study of Chinese patients with MS. ${ }^{19}$ Men had higher overall disability (PDDS), and worse walking and dexterity scores, which is also consistent with the survey of Chinese patients with $\mathrm{MS}^{19}$ and the literature documenting higher burden of spinal disability and higher load of destructive, T1 hypointense lesions in men compared with women (reviewed in reference 20).

African ancestry is a known risk factor for worse outcomes in MS. $^{21,22}$ African Americans have faster disease progression, ${ }^{23}$ especially early in the disease, ${ }^{24}$ and more brain, ${ }^{25,26}$ spinal cord, ${ }^{27}$ and optic nerve ${ }^{28}$ atrophy. In line with these reports, we found that symptom scores were higher in AAs compared with Whites in every domain even after adjusting for age and sex. The literature on MS in Hispanic Americans is sparse. Our prior work showed that HAs have higher disability scores than Whites. ${ }^{29}$ In the present work, we show that HAs had worse scores than Whites in every domains and even higher than in AAs in several domains of invisible disability - pain, cognition, depression, and anxiety.

Given the differences in symptom burden across race/ethnic groups, we hypothesized that race would be an independent predictor of good SRH. However, race/ethnicity was a strong predictor of SRH only if domain scores are not taken into account. In a multivariable model that accounted for age, sex, race/ethnicity, selfreported disability, and individual domain symptom scores, only body pain, depression, fatigue, and PDDS - in the order of decreasing contribution - were predictive of good SRH. Sensitivity of the model was $82 \%$ and specificity $76 \%$. Thus, what determines how patients view their health is not their demographics but symptom severity in domains of invisible disability and, to a much lesser extent, their overall physical disability score (PDDS).

One limitation of our study is that the racial self-identification does not reveal the extent of genetic admixtures in patients' ancestry $^{30}$ and may even conflict with the genetic data. ${ }^{31}$ One can overcome this limitation using ancestry informative genetic markers, but this approach is not feasible in a retrospective, clinic-based study. Another limitation is that clinician-rated measures were not available for our sample; prior studies have validated domain SyMS scores against clinician-rated metrics. ${ }^{12,32,33}$ Third, we did not collect information on patients' socioeconomic status (SES) and are not able determine how much of variance in symptom burden among race/ethnic groups may be due to differences in SES. In our prior work on disability differences in patients with MS from the different racial groups, adjusting for insurance status as a surrogate for SES did not change the results. ${ }^{29}$ However, others have found that failure to account for SES differences may lead to overestimation of differences between racial groups. ${ }^{34}$ We propose that the future observational studies comparing outcomes across ethnoancestries use Area Deprivation Index, which can be derived from patient's address (neighborhoodatlas.medicine.wisc.edu/), as a more nuanced surrogate of SES, and address social determinants of health, which may disproportionately affect minoritized populations that extend beyond SES. ${ }^{35}$ Another limitation is that we did not systematically collect data on diseasemodifying (DMT) and symptomatic therapies. In our prior work, we did not find differences in overall rates of DMT use across ethnic groups, ${ }^{27}$ and in a recent audit of NYU MS Center data, a higher proportion of AAs were receiving high-efficacy 


\section{TAKE-HOME POINTS}

$\rightarrow$ Men and women with MS have similar total symptoms burden. Women were more symptomatic earlier in the disease and reported higher levels of fatigue and anxiety, whereas men scored worse on domains of mobility and dexterity.

$\rightarrow$ African Americans and Hispanic Americans reported higher symptom burden in all 12 domains compared with Whites. Hispanic Americans had higher scores than African Americans on domains of pain, cognition, depression, and anxiety.

$\rightarrow$ Self-rated health was not predicted by sex or race/ ethnicity, but only by scores in domains of body pain, depression, fatigue, and, to a lesser extent, overall disability.

$\rightarrow$ It is plausible that more effective management of pain, depression, and fatigue in MS will lead to a decrease in disparities in self-rated health among race/ethnic groups and improvements in quality of life across all groups.

therapies (natalizumab and anti-CD20 therapies) compared with Whites (data on file) likely in response to their higher disease severity. Thus, it is highly unlikely that observed differences in disease severity are due to undertreatment of minority populations. Finally, the potential impact of various forms of selection bias must be considered. If the more disabled minority patients are preferentially referred to tertiary centers, while milder cases are managed by community neurologists, our minority populations may be skewed toward the more severe end of the spectrum. ${ }^{8}$ Conversely, if the more impaired minority patients are less likely to follow up in the referral center given socioeconomic disparities, the results would be skewed in the opposite direction. The racial representation in our clinics with respect to Whites, AAs, and HAs is reflective of our catchment area, so a considerable referral bias is not likely. Still, clinic patients with MS may differ from the general MS population, and population-based studies covering diverse geographic locales are needed to confirm whether our findings are generalizable.

In conclusion, $\mathrm{AA}$ and $\mathrm{HA}$ race/ethnicity was associated with higher overall disability, higher symptom severity in each of the 12 domains commonly affected by MS, and lower SRH scores relative to Whites. Importantly, race/ethnicity was not a predictor of SRH, rather SRH was mainly predicted by severity of body pain, depression, and fatigue. Our work suggests that improvement in managing these symptoms will be most likely to improve patients' quality of life and to reduce the disparities in SRH among race/ethnic groups. High symptom burden in non-White minorities with MS warrants investigation into its biologic and sociologic causes.

\section{Study Funding}

The study was supported by an unrestricted investigatorinitiated grant from Biogen (US-MSG-17-11284).

\section{Disclosure}

I. Kister served on the scientific advisory boards for Biogen Idec and Genentech; received consulting fees from Roche; and received research support from the Guthy-Jackson Charitable Foundation, the National Multiple Sclerosis Society, Biogen Idec, Serono, Genzyme, and Genentech. T. Bacon reports no disclosures relevant to the manuscript. G.R. Cutter: data and safety monitoring boards-AstraZeneca, Avexis Pharmaceuticals, Biolinerx, Brainstorm Cell Therapeutics, Bristol-Meyers Squibb/Celgene, CSL Behring, Galmed Pharmaceuticals, GreenValley Pharma Ltd., Mapi Pharmaceuticals Ltd., Merck, Merck/Pfizer, Opko Biologics, OncoImmune, Neurim, Novartis, Orphazyme, SanofiAventis, Reata Pharmaceuticals, Teva Pharmaceuticals, Viela Bio, Inc, Vivus, NHLBI (protocol review committee), and NICHD (OPRU oversight committee); and consulting or advisory boards-Biodelivery Sciences International, Biogen, Click Therapeutics, Genzyme, Genentech, GW Pharmaceuticals, Immunic, Klein-Buendel Incorporated, MedImmune/Viela Bio, MedDay, Merck/Serono, Neurogenesis LTD, Novartis, Osmotica Pharmaceuticals, Perception Neurosciences, Recursion/Cerexis Pharmaceuticals, Regeneron, Rekover Therapeutics, Roche, and TG Therapeutics; G.R. Cutter is employed by the University of Alabama at Birmingham and president of Pythagoras, Inc., a private consulting company located in Birmingham, AL. Full disclosure form information provided by the authors is available with the full text of this article at Neurology.org/cp.

\section{Publication History}

Received by Neurology: Clinical Practice December 26, 2020. Accepted in final form April 5, 2021.

\begin{tabular}{|c|c|c|}
\hline Name & Location & Contribution \\
\hline $\begin{array}{l}\text { Ilya Kister, } \\
\text { MD }\end{array}$ & $\begin{array}{l}\text { NYU Multiple Sclerosis } \\
\text { Comprehensive Care Center, } \\
\text { NYU Langone Medical } \\
\text { Center, NY }\end{array}$ & $\begin{array}{l}\text { Drafting/revision of the } \\
\text { manuscript for content, } \\
\text { including medical writing for } \\
\text { content; major role in the } \\
\text { acquisition of data; study } \\
\text { concept or design; and } \\
\text { analysis or interpretation of } \\
\text { data }\end{array}$ \\
\hline $\begin{array}{l}\text { Tamar } \\
\text { Bacon, BA }\end{array}$ & $\begin{array}{l}\text { NYU Multiple Sclerosis } \\
\text { Comprehensive Care Center, } \\
\text { NYU Langone Medical } \\
\text { Center, NY }\end{array}$ & $\begin{array}{l}\text { Drafting/revision of the } \\
\text { manuscript for content, } \\
\text { including medical writing for } \\
\text { content; study concept or } \\
\text { design; and analysis or } \\
\text { interpretation of data }\end{array}$ \\
\hline $\begin{array}{l}\text { Gary R. } \\
\text { Cutter, PhD }\end{array}$ & $\begin{array}{l}\text { Department of Biostatistics, } \\
\text { UAB School of Public Health, } \\
\text { Birmingham, AL }\end{array}$ & $\begin{array}{l}\text { Drafting/revision of the } \\
\text { manuscript for content, } \\
\text { including medical writing for } \\
\text { content; study concept or } \\
\text { design; and analysis or } \\
\text { interpretation of data }\end{array}$ \\
\hline
\end{tabular}




\section{References}

1. Smith KJ, McDonald WI. The pathophysiology of multiple sclerosis: the mechanism underlying the production of symptoms and the natural history of the disease. Philos Trans R Soc Lond B Biol Sci. 1999;354(1390):1649-1673.

2. de Sa JC, Airas L, Bartholome E, et al. Symptomatic therapy in multiple sclerosis: review for a multimodal approach in clinical practice. Ther Adv Neurol Disord. 2011 4(3):139-168.

3. Kister I, Bacon TE, Chamot E, et al. Natural history of multiple sclerosis symptoms. Int J MS Care. 2013;15(3):146-158.

4. Langer-Gould A, Brara SM, Beaber BE, Zhang JL. Incidence of multiple sclerosis in multiple racial and ethnic groups. Neurology. 2013;80(19):1734-1739.

5. Wallin MT, Culpepper WJ, Coffman P, et al. The Gulf War era multiple sclerosis cohort: age and incidence rates by race, sex and service. Brain. 2012;135(pt 6): 1778-1785.

6. Khan O, Williams MJ, Amezcua L, Javed A, Larsen KE, Smrtka JM. Multiple sclerosis in US minority populations: clinical practice insights. Neurol Clin Pract. 2015;5(2): $132-142$.

7. Fabius CD, Thomas KS, Zhang T, Ogarek J, Shireman TI. Racial disparities in Medicaid home and community-based service utilization and expenditures among persons with multiple sclerosis. BMC Health Serv Res. 2018;18(1):773.

8. Shabas D, Heffner M. Multiple sclerosis management for low-income minorities. Mult Scler. 2005;11(6):635-640

9. Minden SL, Hoaglin DC, Hadden L, Frankel D, Robbins T, Perloff J. Access to and utilization of neurologists by people with multiple sclerosis. Neurology. 2008;70(13 pt 2):1141-1149.

10. Hohol MJ, Orav EJ, Weiner HL. Disease Steps in multiple sclerosis: a simple approach to evaluate disease progression. Neurology. 1995;45:251-255.

11. Learmonth YC, Motl RW, Sandroff BM, Pula JH, Cadavid D. Validation of patient determined disease steps (PDDS) scale scores in persons with multiple sclerosis. BMC Neurol. 2013;13:37.

12. Green R, Kalina J, Ford R, Pandey K, Kister I. SymptoMScreen: a tool for rapid assessment of symptom severity in MS across multiple domains. Appl Neuropsychol Adult 2017;24(2):183-189.

13. Buchanan RJ, Chakravorty BJ, Tyry T, Hatcher W, Vollmer T. Age-related comparisons of people with multiple sclerosis: demographic, disease, and treatment characteristics. NeuroRehabilitation. 2009;25(4):271-278

14. Wood B, van der Mei IA, Ponsonby AL, et al. Prevalence and concurrence of anxiety, depression and fatigue over time in multiple sclerosis. Mult Scler. 2013;19(2):217-224

15. Kalincik T, Vivek V, Jokubaitis V, et al. Sex as a determinant of relapse incidence and progressive course of multiple sclerosis. Brain. 2013;136(pt 12):3609-3617.

16. Tremlett H, Zhao Y, Joseph J, Devonshire V; UBCMS Clinic Neurologists. Relapses in multiple sclerosis are age- and time-dependent. J Neurol Neurosurg Psychiatry. 2008; 79(12):1368-1374.

17. Pozzilli C, Tomassini V, Marinelli F, Paolillo A, Gasperini C, Bastianello S. 'Gender gap' in multiple sclerosis: magnetic resonance imaging evidence. Eur J Neurol. 2003; 10(1):95-97.
$\mathrm{Li} \mathrm{SH}$, Graham BM. Why are women so vulnerable to anxiety, trauma-related and stressrelated disorders? The potential role of sex hormones. Lancet Psychiatry. 2017;4(1):73-82

19. Zhao Z, Zhang $\mathrm{Y}$, Du $\mathrm{Q}$ et al. Differences in physical, mental, and social function between males and females in multiple sclerosis: a multicenter cross-sectional study in China. Mult Scler Relat Disord. 2021;48:102693.

20. Gilli F, DiSano KD, Pachner AR. SeXX matters in multiple sclerosis. Front Neurol. 2020;11:616.

21. Aurenção JC, Vasconcelos CC, Thuler LC, Alvarenga RM. Disability and progression in Afro-descendant patients with multiple sclerosis. Arq Neuropsiquiatr. 2016;74(10): 836-841.

22. Cipriani VP, Klein S. Clinical characteristics of multiple sclerosis in African-Americans. Curr Neurol Neurosci Rep. 2019;19(11):87.

23. Kister I, Chamot E, Bacon JH, et al. Rapid disease course in African Americans with multiple sclerosis. Neurology. 2010;75(3):217-223.

24. Alsaeed MO, Harding KE, Williams OH, et al. Multiple sclerosis: long-term outcomes in ethnic minorities. Analysis of a UK population-based registry. Eur J Neurol. 2018; 25(4):701-704.

25. Weinstock-Guttman B, Ramanathan M, Hashmi K, et al. Increased tissue damage and lesion volumes in African Americans with multiple sclerosis. Neurology. 2010;74(7):538-544.

26. Howard J, Battaglini M, Babb JS, et al. MRI correlates of disability in AfricanAmericans with multiple sclerosis. PLoS One. 2012;7(8):e43061.

27. Moog TM, McCreary M, Stanley T, et al. African Americans experience disproportionate neurodegenerative changes in the medulla and upper cervical spinal cord in early multiple sclerosis. Mult Scler Relat Disord. 2020;45:102429.

28. Caldito NG, Saidha S, Sotirchos ES, et al. Brain and retinal atrophy in AfricanAmericans versus Caucasian-Americans with multiple sclerosis: a longitudinal study. Brain. 2018;141(11):3115-3129.

29. Ventura RE, Antezana AO, Bacon T, Kister I. Hispanic Americans and African Americans with multiple sclerosis have more severe disease course than Caucasian Americans. Mult Scler. 2017;23(11):1554-1557.

30. Amezcua L, McCauley JL. Race and ethnicity on MS presentation and disease course. Mult Scler. 2020;26(5):561-567.

31. Mersha TB, Abebe T. Self-reported race/ethnicity in the age of genomic research: its potential impact on understanding health disparities. Hum Genomics. 2015;9(1):1.

32. Fitzgerald KC, Salter A, Tyry T, et al. Validation of the SymptoMScreen with performance-based or clinician-assessed outcomes. Mult Scler Relat Disord. 2019;29: $86-93$.

33. Meca-Lallana J, Maurino J, Hernández-Pérez MÁ, et al. Psychometric properties of the SymptoMScreen questionnaire in a mild disability population of patients with relapsing-remitting multiple sclerosis: quantifying the patient's perspective. Neurol Ther. 2020;9(1):173-179.

34. Marrie RA, Cutter G, Tyry T, Vollmer T, Campagnolo D. Does multiple sclerosisassociated disability differ between races? Neurology. 2006;66(8):1235-1240.

35. Roddam H, Rog D, Janssen J, et al. Inequalities in access to health and social care among adults with multiple sclerosis: a scoping review of the literature. Mult Scler Relat Disord. 2019;28:290-304

\section{Practical Implications}

Neurology ${ }^{\oplus}$ Clinical Practice is committed to providing clinical insights helpful to neurologists in everyday practice. Each Full Case includes a "Practical Implications" statement, a pearl of wisdom for the practicing clinician. 


\title{
Neurology Clinical Practice
}

\author{
How Multiple Sclerosis Symptoms Vary by Age, Sex, and Race/Ethnicity \\ Ilya Kister, Tamar Bacon and Gary R. Cutter
}

Neurol Clin Pract 2021;11;335-341 Published Online before print May 28, 2021

DOI 10.1212/CPJ.0000000000001105

This information is current as of May 28, 2021

\section{Updated Information \& \\ Services}

\section{References}

Citations

Subspecialty Collections

Permissions \& Licensing

Reprints including high resolution figures, can be found at:

http://cp.neurology.org/content/11/4/335.full.html

This article cites 35 articles, 8 of which you can access for free at: http://cp.neurology.org/content/11/4/335.full.html\#\#ref-list-1

This article has been cited by 3 HighWire-hosted articles:

http://cp.neurology.org/content/11/4/335.full.html\#\#otherarticles

This article, along with others on similar topics, appears in the following collection(s):

All Demyelinating disease (CNS)

http://cp.neurology.org//cgi/collection/all_demyelinating_disease_cns

Health disparities

http://cp.neurology.org//cgi/collection/health_disparities

Inclusion, Diversity, Equity, Anti-racism, and Social Justice (IDEAS)

http://cp.neurology.org//cgi/collection/all_equity_diversity_and_inclusion

Multiple sclerosis

http://cp.neurology.org//cgi/collection/multiple_sclerosis

Risk factors in epidemiology

http://cp.neurology.org//cgi/collection/risk_factors_in_epidemiology

Information about reproducing this article in parts (figures,tables) or in its entirety can be found online at:

http://cp.neurology.org/misc/about.xhtml\#permissions

Information about ordering reprints can be found online:

http://cp.neurology.org/misc/addir.xhtml\#reprintsus

Neurol Clin Pract is an official journal of the American Academy of Neurology. Published continuously since 2011, it is now a bimonthly with 6 issues per year. Copyright Copyright (c) 2021 The Author(s). Published by Wolters Kluwer Health, Inc. on behalf of the American Academy of Neurology.. All rights reserved. Print ISSN: 2163-0402. Online ISSN: $2163-0933$.

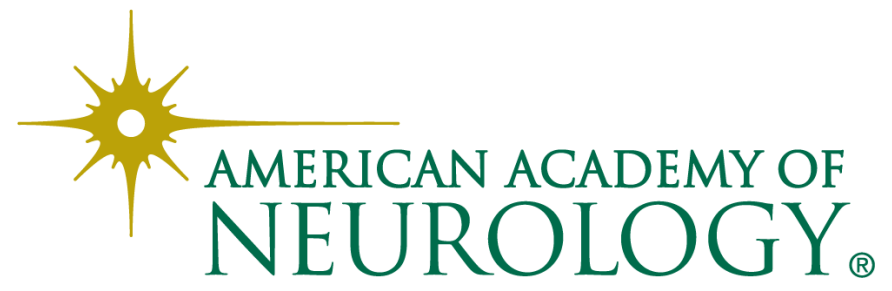

